\title{
iMakerSpace Best Practices for Shaping the 21st Century Workforce
}

\author{
Ismail Fidan ${ }^{1, *}\left(\mathbb{D}\right.$, Stephen Canfield ${ }^{2}$, Vahid Motevalli ${ }^{2}$, George Chitiyo ${ }^{3}$ and Mahdi Mohammadizadeh ${ }^{4}$ \\ 1 Department of Manufacturing and Engineering Technology, College of Engineering, \\ Tennessee Tech University, Cookeville, TN 38505, USA \\ 2 Department of Mechanical Engineering, College of Engineering, Tennessee Tech University, \\ Cookeville, TN 38505, USA; scanfield@tntech.edu (S.C.); vmotevalli@tntech.edu (V.M.) \\ 3 Department of Curriculum and Instruction, College of Education, Tennessee Tech University, \\ Cookeville, TN 38505, USA; gchitiyo@tntech.edu \\ 4 Center for Manufacturing Research and Department of Mechanical Engineering, College of Engineering, \\ Tennessee Tech University, Cookeville, TN 38505, USA; mmohammad42@tntech.edu \\ * Correspondence: ifidan@tntech.edu; Tel.: +1-931-372-6298
}

check for updates

Citation: Fidan, I.; Canfield, S.;

Motevalli, V.; Chitiyo, G.;

Mohammadizadeh, M. iMakerSpace Best Practices for Shaping the 21st Century Workforce. Technologies 2021,

9, 32. https://doi.org/10.3390/

technologies 9020032

Academic Editor: Manoj Gupta

Received: 26 March 2021

Accepted: 9 April 2021

Published: 28 April 2021

Publisher's Note: MDPI stays neutral with regard to jurisdictional claims in published maps and institutional affiliations.

Copyright: (C) 2021 by the authors. Licensee MDPI, Basel, Switzerland. This article is an open access article distributed under the terms and conditions of the Creative Commons Attribution (CC BY) license (https:// creativecommons.org/licenses/by/ $4.0 /)$.

\begin{abstract}
Innovations in engineering education are undergoing a noticeable transformation. Higher education institutions are practicing distance education, remote laboratories, studio pedagogies and several other approaches in order to increase their students' retention, success, and preparedness for the job market. In engineering education, maker spaces have become popular in the last ten years in universities as well as community colleges, high schools and community innovation hubs. A large number of engineering colleges have allocated significant spaces, and at some universities entire buildings, as maker spaces to be used for curricular and extracurricular activities. Success stories of these types of spaces are well documented. This paper describes the core activities and programs held at Tennessee Tech University's maker space called 'iMakerSpace.' Accomplishments include several innovative workforce development activities. The impact and effectiveness of the iMakerSpace, presented through workforce innovations and survey statistics, is a unique contribution to this paper. In addition, the modification of operations under COVID-19 pandemic restrictions has resulted in changes that may be carried out post-pandemic.
\end{abstract}

Keywords: innovation; maker space; iMakerSpace; 3D printing; COVID-19; workshop; manufacturing; skill; entrepreneurship

\section{Introduction}

Maker Spaces (MSs) are physical spaces located in community settings or educational institutions for group collaboration and social learning on innovative and technological projects $[1,2]$. MSs are becoming increasingly popular worldwide due to the high potential for fostering essential skills needed for innovation and advancing creativity [2,3]. They are collaborative environments inside a university, school, library or dedicated public or private facility for learning, exploring, making and sharing, that use high-tech to no tech tools $[1,4]$. They are accessible to students, the public and entrepreneurs. These spaces are equipped with a variety of maker equipment including 3D printers, laser cutters, Computer Numerical Control (CNC) machines, soldering stations, hand tools etc. [5]. These facilities can take the form of for-profit companies, non-profit corporations, organizations affiliated with or hosted within schools, universities or libraries, and more [6,7]. In this paper, the activities and innovations taking place in the iMakerSpace during the COVID-19 (known as Coronavirus Disease 2019, first identified in Wuhan, China, in December 2019. In COVID-19, 'CO' stands for 'corona,' 'VI' for 'virus,' and 'D' for disease) pandemic are reported and discussed. Several innovative activities implemented in the space are presented, and the effectiveness of these activities are evaluated using data collected from survey tools. 
The beginning of MSs can be traced back to Germany in 1995, when the first maker space called C-Base was launched. This started as a place in the community where computer programmers would meet, work, and share their ideas in a place that they called a "hackerspace." Over the years, the price of maker tools such as 3D printers, desktop laser cutters and $\mathrm{CNC}$ routers became more affordable, and hackerspaces naturally evolved into MSs. The MS idea is believed to have started in the US with the emergence of the Make magazine in 2005, a magazine in the field of innovative manufacturing. Eventually, the movement grew when the Make magazine started a series of venues for makers to express themselves and share their creations; these venues were named "maker faire" [8]. Libraries began offering programs and redesigning spaces to address related interests within their communities [9]. Reviews of university MSs demonstrate growing understanding of the impact of these spaces on undergraduate education [10,11].

A library MS is a successful example of the maker space movement in universities, which offers students an opportunity to participate in developing innovative projects [12]. In an MS, students are empowered to use collaborative facilities and social connections, in addition to conventional instructional guidance and technical facilities to explore innovation [13-16].

These spaces are intended to generate interest in science, technology, design, and lifelong learning for the general public [17]. They also provide minorities and underrepresented populations, [17], such as people with disabilities, opportunities to become involved with technology and fields that may not have previously been available to them. The community atmosphere of MSs allows patrons to learn from each other and to experiment [18]. University MS activities promote hands-on skills for students to support their theoretical coursework in engineering and other related disciplines. Other observed achievements include improving creativity, team-oriented problem-solving, and multidisciplinary collaboration skills $[19,20]$. MSs improve critical thinking skills and boost the self-confidence of learners [21]. Some of the skills that are learned in an MS pertain to electronics, 3D printing (3DP), 3D modeling, coding, robotics, and even woodworking. These spaces also foster entrepreneurship, and are being utilized as incubators and accelerators for business startups [22].

This paper describes several innovations and best practices observed and documented at an MS located at Tennessee Tech University during the COVID-19 outbreak years. The innovations and activities focused on helping students and other users develop several soft skills and practical knowledge to prepare them for the 21st century workforce will be described here.

\section{2. iMakerSpace}

The MS at Tennessee Tech is located in the university library and is known as iMakerSpace. It is a university-wide, student-centered space supported by the College of Engineering with ongoing support from, and collaboration with, the College of Business. The iMakerSpace serves as a focal point on campus to provide cutting-edge education, service, partnership, research, and Innovation and Entrepreneurship (I\&E) activities for all disciplines. iMakerSpace encourages interdisciplinary teams and provides support and education to extend I\&E activities into research and the classroom. The iMakerSpace occupies a $2000+$ square foot collaborative and fabrication space.

The iMakerSpace serves three general groups:

- The university community (students, faculty and staff),

- Maker Members (students that undergo special training to operate iMakerSpace equipment at an advanced level), and

- the general public.

All three groups are welcome and encouraged to utilize the iMakerSpace and its facilities. It is open Monday through Friday from 8:00 AM to 4:30 PM to the university community as well as the public. The staff, comprised of an engineering graduate student, a part-time R\&D engineer, a faculty director, and a team of trained undergraduate students, 
are available to support the iMakerSpace activities. Access to the iMakerSpace outside of regular hours is restricted to Maker Members as long as the library is open.

21st Century Workforce is a general term that encompasses a number of high-tech labor forces from Cybersecurity to 3DP. The activities provided by the iMakerSpace are broadly focused on 3DP and its usage in several fields of study. Participants (faculty, staff, and students) of the iMakerSpace events learn and implement the cutting-edge practices of Solid Modeling, 3DP, and I\&E.

\section{Background}

Since its establishment in 2015, the iMakerSpace has increased both services and outreach activities to further provide students, faculty, and staff with the resources for effective instruction, hands-on and project-based learning, and research projects. Figure 1 demonstrates the area in the iMakerSpace allocated for lectures and discussion. Figure 2 shows the space allocated for fabrication and small-scale work. Figure 3 presents the area accommodating several 3D printers which are accessible remotely via iMakerTrack.

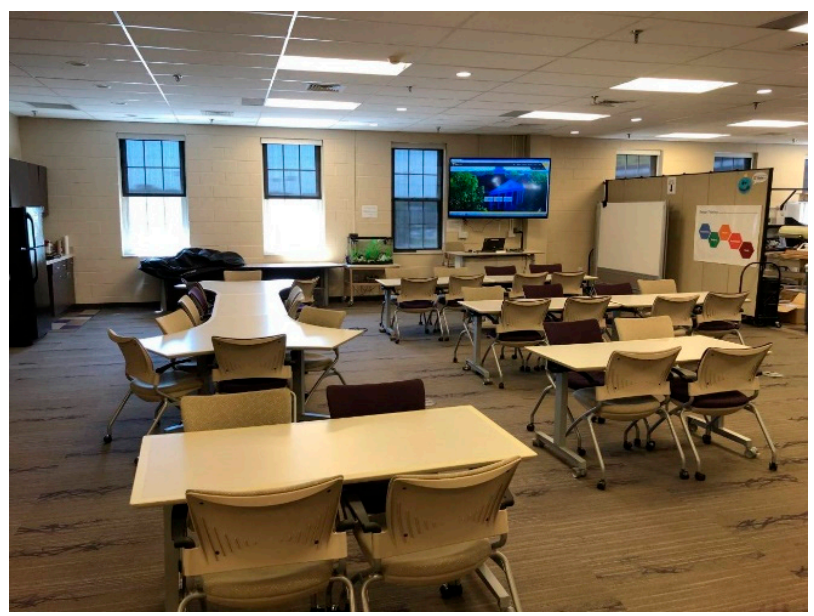

Figure 1. iMakerSpace Studio for team meetings and discussions, lectures, and events.

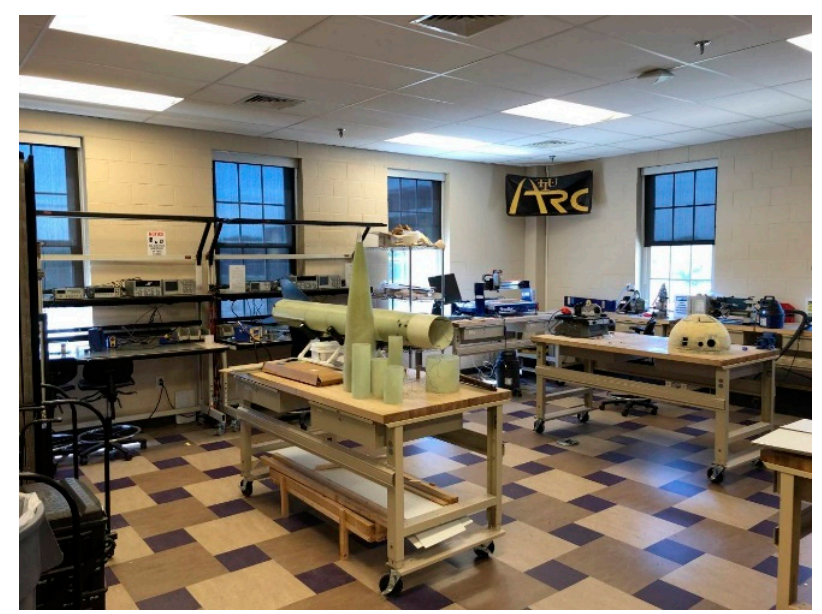

Figure 2. Fabrication and student club area of iMakerSpace. 


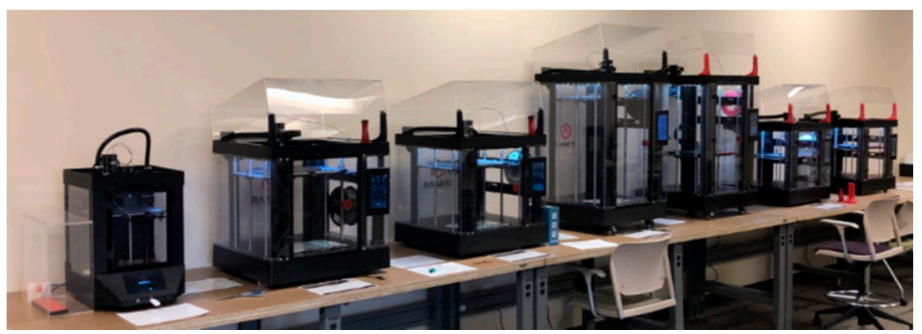

Figure 3. 3D printing (3DP) section of iMakerSpace.

The iMakerSpace provides various services to the entire campus. The meeting area can be used for team meetings and discussions, lectures and events. The workshop space provides an environment where both individuals and teams can utilize the equipment, supplies, and resources for projects. The 3DP section of the MS has a number of printers running with Fused Filament Fabrication and Stereolithographic techniques. Due to the iMakerSpace's combination of education, learning-by-doing, and fabrication, several I\&E events utilize the facility for lectures, training and student competitions. Student senior design and capstone projects are fabricated with the support of the iMakerSpace team.

Activities in the iMakerSpace are developed by its management team, and the activity task work is distributed. Execution and standing of these activities are reviewed with face-to-face and virtual meetings every week. In Fall 2020, the management team also established an advisory board. Advisory board members were selected from the active faculty members who have been using the MS from several departments of the university. The objective of the advisory board is to receive inputs from diverse group of faculty members and continuously improve the functionality of the MS.

The following section provides a list of available equipment and resources.

- $\quad$ Seven Raise3D printers: advanced additive manufacturing-large build volume, highresolution, power failure recovery, filament run-out sensor, digital monitoring, dual print heads.

- Two FormLabs printers: advanced additive manufacturing-laser-based, extreme precision, ultra-high quality.

- Two Monoprice printers: hobbyist additive manufacturing-smaller build volume, reliable quality, perfect for beginners to experiment with.

- $\quad$ Two CNC: cutting area, ability to cut wood, plastic, and soft metals.

- One ZMorph Hybrid Manufacturing System: 3DP, Laser Cutting and CNC Mill.

- Four desktop computers: equipped with appropriate hardware and the most up-todate software, used for 2D and 3D modeling.

- $\quad$ Nine low-top desks: able to arrange in many configurations.

- $\quad$ Four high-top work stations: large workshop tables to accommodate projects.

- Two display screens: high definition, computer input friendly, easy to use.

- $\quad$ Seven mobile white boards: large dry-erase surface for drawing and writing, arrangeable.

- $\quad$ One studio: space accommodating 50 people

- Hand tools: large assortment of both manual and powered hand tools.

- One instruction station with laptop hook-up

- One electronics and soldering station

\section{4. iMakerSpace Innovations}

iMakerSpace hosts a large number of unique activities throughout the year. The basic challenge and problem identified by the management team was to operate the MS successfully with the tight COVID-19 restrictions. Its operation was successfully performed in 2020 and 2021 due to the very well-structured teamwork of the management. This paper highlights the following selected core activities. 


\subsection{Golden Eagle Additively Innovative Virtual Lecture Series}

The iMakerSpace is home to the "Golden Eagle Additively Innovative Lecture Series." These lectures are each about a half hour long and feature guest speakers from all around the world. The lectures are open to anyone via the free Zoom platform. Listeners can hear experts in their fields talk about additive manufacturing and other related processes. To tune in, participants can use an easy-access link at any of the times listed in the lecture series. This program has been active for the past five years and it has helped to train a high number of people on the latest trends and technologies of additive manufacturing. Students who are interested in attending the lectures via the iMakerSpace studio are also encouraged to do so.

All of the lectures are also recorded and placed on a server maintained by the Center for Manufacturing Research [23]. Eventually, lectures are also disseminated via a YouTube Channel [24]. It was observed that the lecture series had attendees from all over the world, from India to Azerbaijan, Australia, Brazil, Canada and England. University students also indicated that these talks were beneficial to them as they helped them enhance their learning of todays' R\&D and workforce needs in additive manufacturing. In Spring 2020, the team creating this virtual lecture series were awarded with the College of Engineering Innovation Award [25]. Figure 4 presents the Spring 2021 Lecture Series.

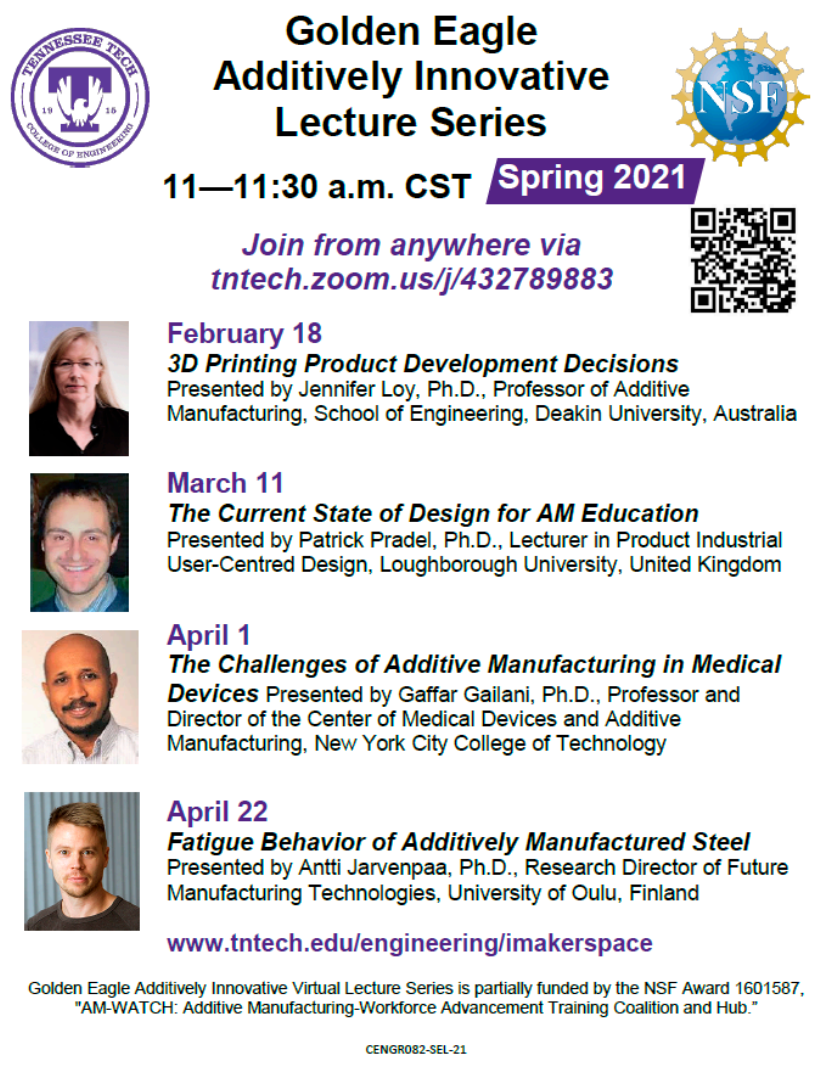

Figure 4. Flyer for the Spring 2021 Golden Eagle Additively Innovative Virtual Lecture Series.

\subsection{Computer Aided Design Workshops}

iMakerSpace hosts a series of Computer-Aided-Design (CAD) workshops for both Tennessee Tech students and non-Tennessee Tech students. In 2019, three workshops were organized. Each workshop was about five hours long and gave participants a basic understanding of SolidWorks, Inventor, and AutoCAD design software tools. At the end of each workshop, participants were given a certificate of completion by the University. The goal of the workshops was to give participants an idea of how each program works, as well as some tips and tricks of the design process. 
The workshops provided some foundational knowledge for the attending students. Students indicated that the workshops helped them increase their design skill sets and capabilities. Since this program needed to have extra certification and had continuing education credit responsibilities, the registration and certification tasks were managed by the Office of Extended Programs and Regional Development. Figure 5 shows the workshops offered in 2019.

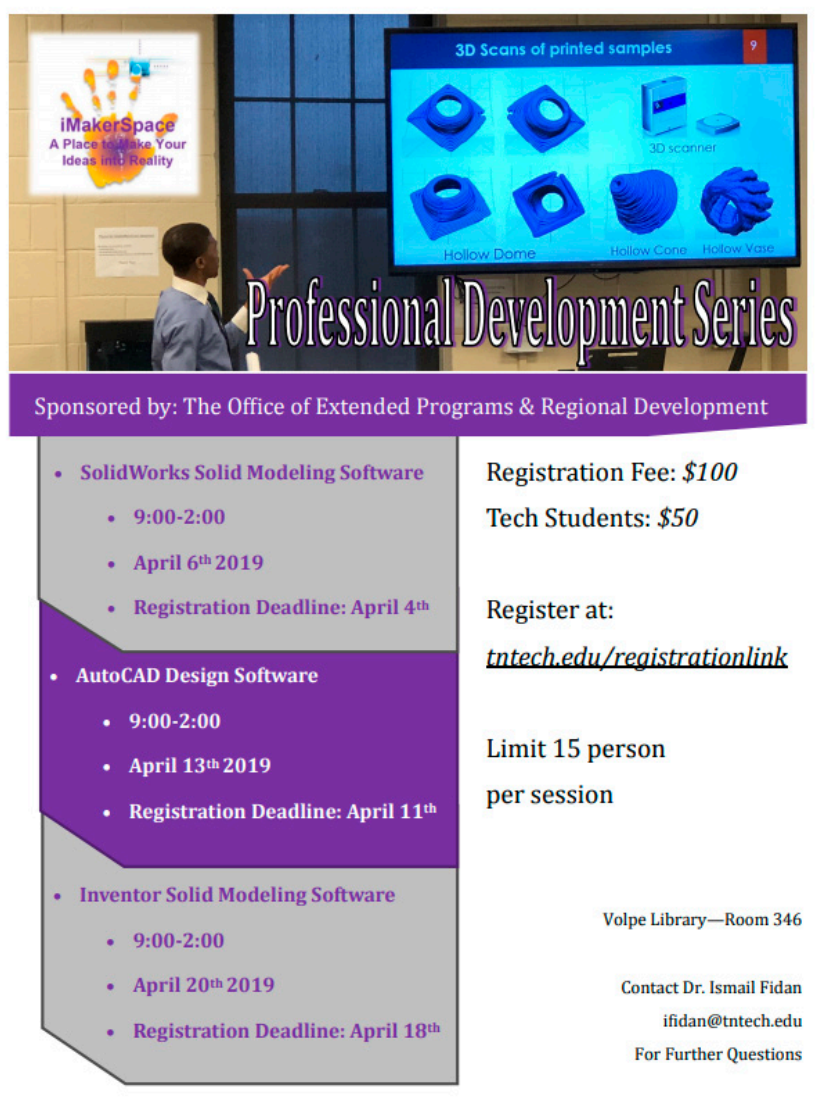

Figure 5. Computer Aided Design Workshops offered in Summer 2019.

\subsection{Summer Workshops}

iMakerSpace hosts a number of workshops, studios, and workforce development activities during the summer months. These two-day events are part of externally funded research projects disseminating the findings of several additive manufacturing and digital manufacturing projects funded by the Advanced Technological Education (ATE) Division of the National Science Foundation (NSF). Participants, who are educators at high schools, community colleges, and universities, come from several states in the US, e.g., Alabama, Florida, Georgia, Kentucky, Ohio, Tennessee, and Washington. The training events are framed with several hands-on activities, and guest speakers come from the partnering institutions of the funded projects.

The scope of the workshops delivered in the summer months was of hands-on training in additive manufacturing, digital manufacturing, virtual reality and smart manufacturing. In all workshops, after the fundamental concepts were delivered, a number of active learning practices were provided. Teams were formed, and attendees who were from various STEM disciplines built their 3D printers, learned the maintenance issues of 3D printers, and used DELL Visor headsets in programming and practicing several VR programs. Figure 6 presents the attendees' practice in using DELL Visor VR Headsets. Figure 7 shows the participants of one Summer 2019 Additive Manufacturing Studio Workshop. 


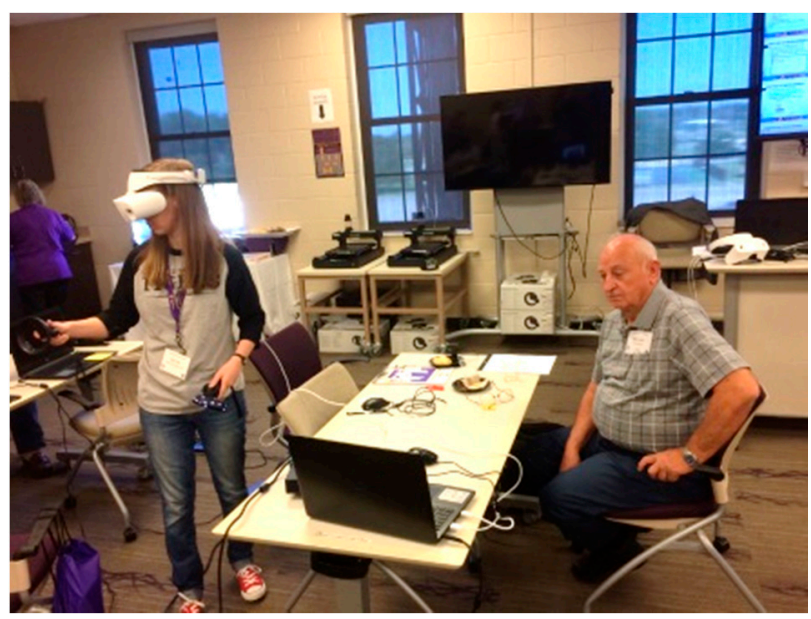

Figure 6. Summer 2019 workshop attendees learning about virtual reality and using DELL Visor headsets.

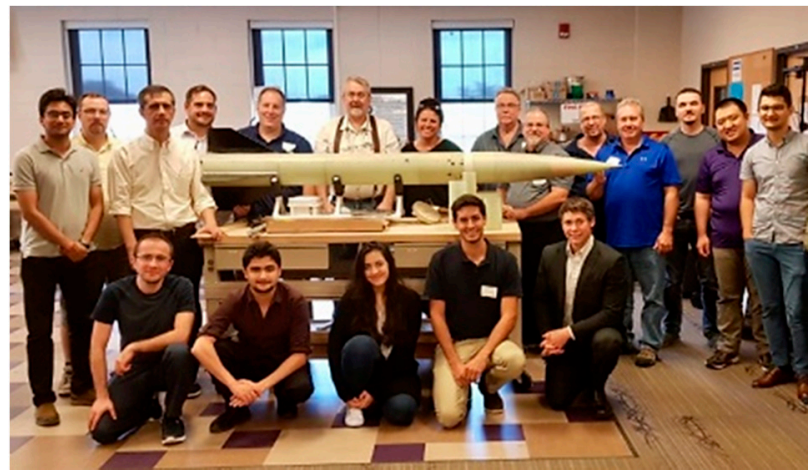

Figure 7. Attendees of the Summer 2019 Additive Manufacturing Studio Workshop.

\subsection{Supporting Student Extracurricular Activities}

iMakerSpace is used by several campus organizations as a meeting space or fabrication unit for their project related tasks and deliverables. These organizations are also active in building prototypes and presenting their projects to prospective students, their families and K-12 students.

The iMakerSpace is the home of two campus student organizations: Students for the Exploration and Development of Space (SEDS), and the Autonomous Robotics Club (ARC). SEDS is an award-winning group which takes part in rocket competitions and high-altitude rocket competitions. ARC is currently working on many robotics projects, such as the Totally Autonomous Legless Useful System (TALUS) which, when complete, will be an interactive greeting system able to answer questions from visitors and also able to shake their hand. SEDS and ARC have joined forces to design a rocket and a 3D printed hover drone to explore other planets, whereby this rocket can successfully carry the drone to its destination. Figure 8 demonstrates ARC Students working for a competition in iMakerSpace.

\subsection{Hosting Eagle Works Activities}

The iMakerSpace hosts a series of workshops for the Tennessee Tech I\&E Competition, the "Eagle Works," an event for aspiring entrepreneurs first launched in the Spring of 2015. These free events are usually held on Wednesdays at 5 PM in the iMakerSpace on the dates provided on the Tennessee Tech website. These workshops talk about topics such as effective communication and branding. These events are extremely helpful for students who want to get involved with Eagle Works [26]. 


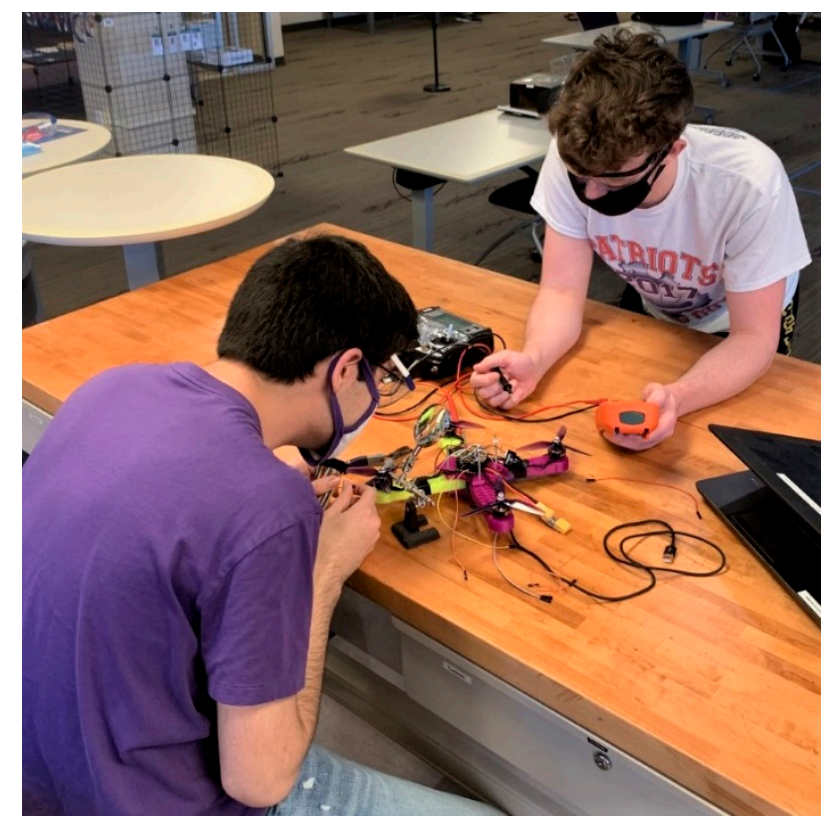

Figure 8. ARC students working for a competition.

Figure 9 shows the training activities held in Spring 2020 to prepare the campus students for the Eagle Works competition.

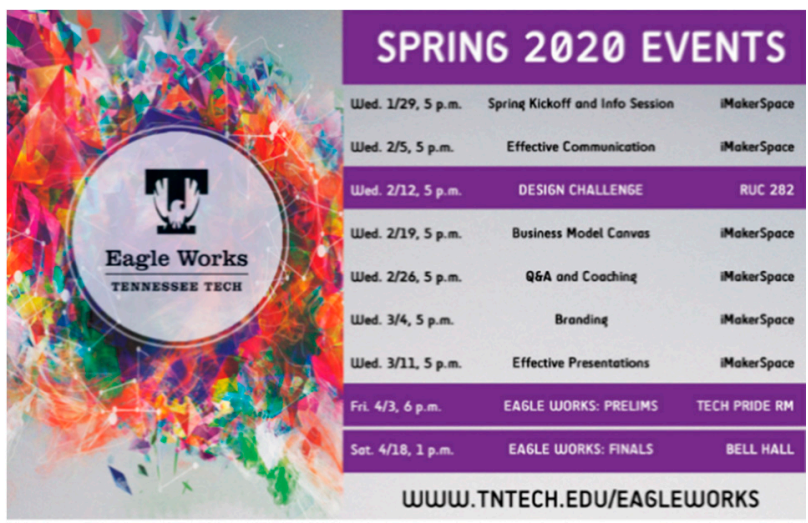

Figure 9. Spring 2020 programs hosted by iMakerSpace.

\subsection{Celebrating Annual Manufacturing Day}

Manufacturing Day takes place on the first Friday of October, and is a celebration of American manufacturing and an opportunity for manufacturers to educate people on the topic. The Tennessee Tech iMakerSpace has held manufacturing day events since 2016. These events showcase work from both Tennessee Tech students and industry partners with the goal of showing what manufacturing has to offer.

Activities during the Manufacturing Day included several student manufacturing research and capstone projects presenting their unique accomplishments, and networking with the regional manufacturing industry representatives and educators. Food and refreshments were served with support provided by the senior SME chapter (sme43.com) or national SME (sme.org). Figure 10 shows a snapshot from the high school students' award program held at the Manufacturing Day 2019. 


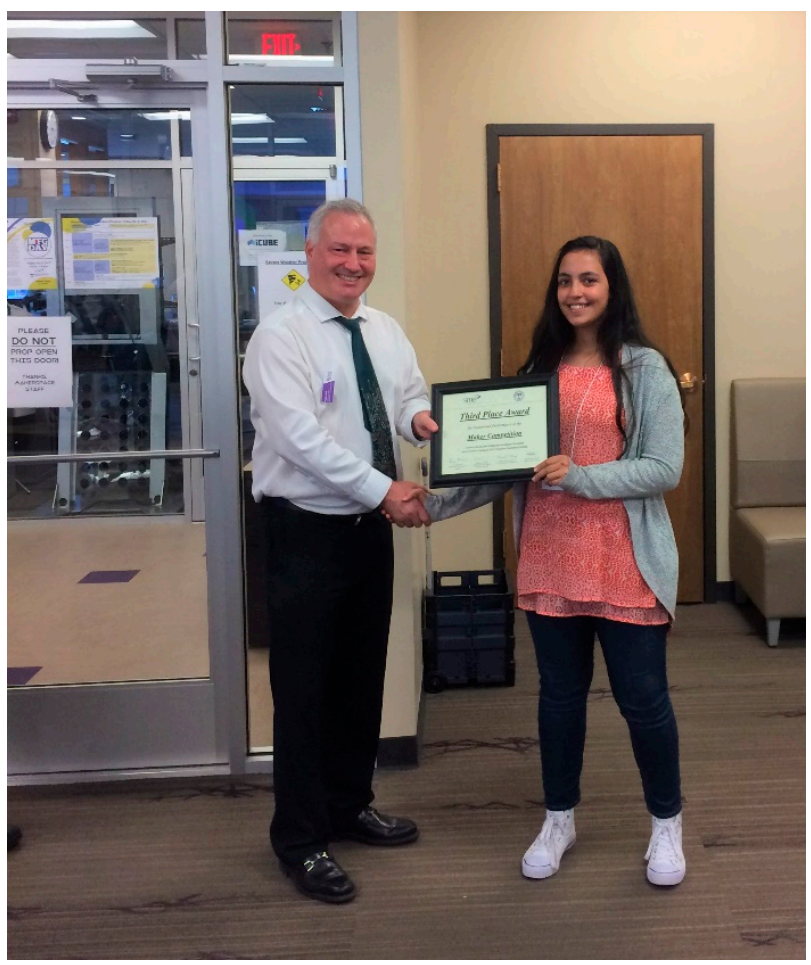

Figure 10. High School Award Program of the Manufacturing Day 2019 held at iMakerSpace Studio.

\section{Changes Made Due to COVID-19}

During COVID-19, the iMakerSpace remained open to accommodate course projects, student needs, and community outreach. The following measures were implemented to abide by the state legislature's health requirements.

- $\quad 3 D$ print requests were submitted remotely through the iMakerTrack system and picked up with limited social contact. On-ground fabrication services were provided with limited capacity as can be seen in Section 7 .

- High volume production needs were accommodated with the approval of the management team.

- $\quad$ Outreach and group tours were suspended, and the University established guidelines that were followed when any tour was held.

- The management team meetings and workforce development workshops were conducted in virtual format.

\section{6. iMakerTrack}

As seen in Figure 11, iMakerTrack is the online part of the design file submission system created to systemize and automate the 3DP fabrication tasks of the unit. The system can be accessed through its website at: https: / /ttuicube.com/3dprint (accessed on 5 April 2021). This submission tool is designed to improve the efficiency of printing projects for research, showcases, and class projects through remote submission of 3DP requests. Due to the growing number of the student clientele and the increasing 3D printing implementation in classes, the development of such a system was essential. Prior to implementing iMakerTrack, students had to find time out of their busy schedules, navigate to find the iMakerSpace, and design what they needed, hoping a printer was available to use. This unique remote system has reduced the problem significantly by allowing students to submit their designs online and let the iMakerSpace staff handle the rest. The management team has noted a decrease in printer problems after the implementation of this system. Furthermore, by using this online submission tool, grouping multiple submitted prints for one printing session becomes easier, leading to a reduction of time and power consumption. 


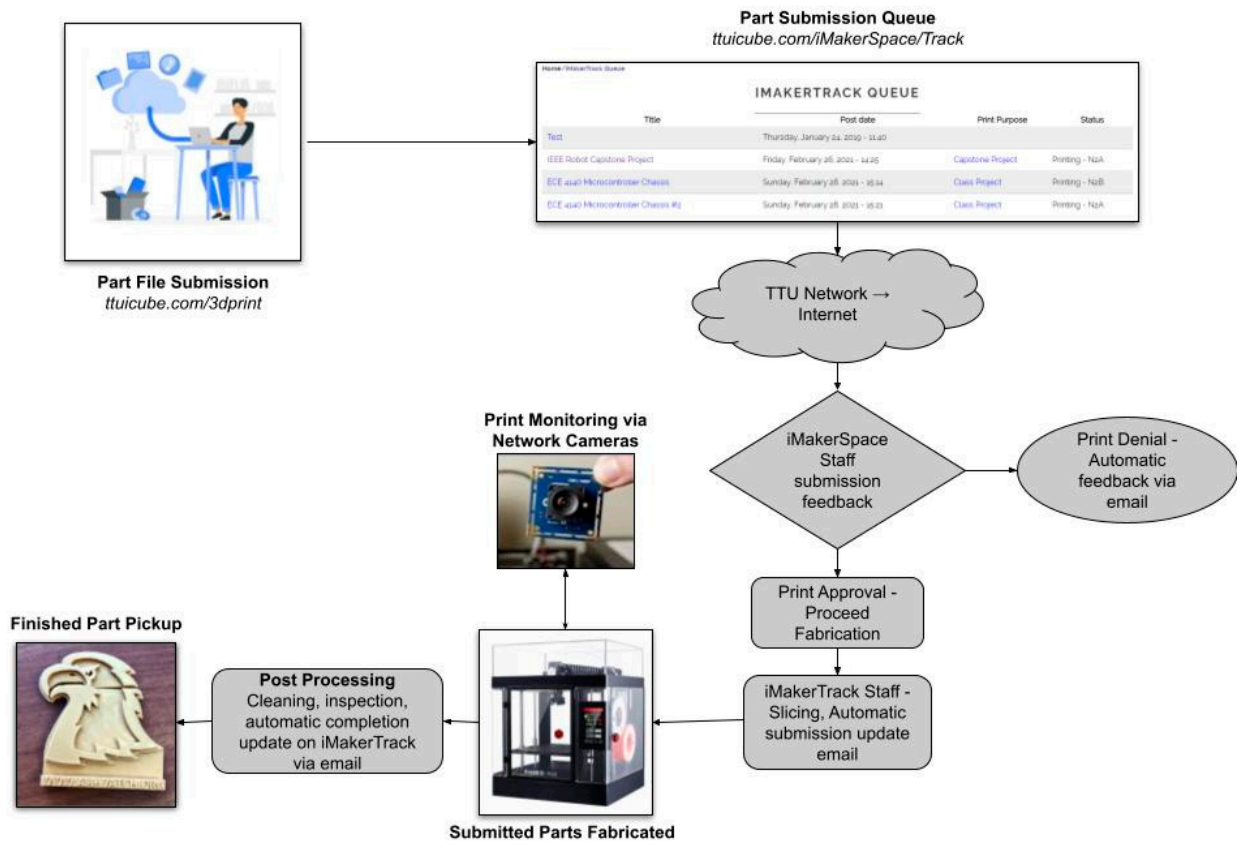

Figure 11. Structure of the iMakerTrack system.

iMakerTrack has the following features to automate the operation of its tasks.

- Online submission of fabrication requests

- Online tracking of job queuing

- Online status monitoring of 3D printers

- Email alerts to students who are tasked to handle the fabrication operation

- Online monitoring of filament usage

- Historical and statistic data extraction and report generation.

The current version of iMakerTrack is an outcome of collective contributions from a number of developers in the iMakerSpace. The beta version was designed from scratch and developed in Fall 2017 and Spring 2018 by a computer science Capstone Design team supervised by an iMakerSpace staff. A number of iMakerSpace team members made tremendous modifications to turn the beta version into the current version. This project is an example of the successful teamwork of multi-disciplinary individuals.

The iMakerTrack system also helps the unit administration and users generate a number of data related to the outcomes of iMakerSpace.

\section{COVID-19 Outbreak Impact}

Just as curricular instruction changed under University guidelines in response to the COVID-19 outbreak, the TTU MS developed an operational plan in order to meet the ongoing needs of the campus community (students, faculty, and staff). The primary modification was to divide the MS use into two categories, those that could be managed remotely and those that required in-person use of the MS. The web-based 3DP tool formed the core of the virtual or remote MS. MS users could collaborate with MS staff through email or online meetings to get help in designing their products, and then submit their completed designs online for manufacture by MS staff through iMakerTrack (Section 6). The webtool also allowed designers to track the process of their product build. For in-person use of the MS, the following operational rules for the space were implemented to allow ongoing safe operation:

- Facilities, equipment, and service are open to all students, faculty, and staff but may be in a reduced operational capacity in the absence of student workers as given below:

Monday-Friday: 8 a.m.-4:30 p.m.

Weekends: closed 
- Use of a face mask is required inside the facility.

- Social distancing rules are strictly enforced while operating the machines, equipment, and tools, and while using the studio.

- No food and drink are allowed.

- Maximum number of the people allowed inside the space is 10.

- Club meetings and workshops should be conducted virtually if the number of participants is over 10 .

- Equipment and studio tables are sanitized after each use.

- Graduate assistants hold regular office hours in online and in-person settings due to the needs of the campus community.

- The iMakerSpace keeps accepting digital print submissions through iMakerTrack.

- Students should follow all recommended hygiene procedures and clean areas with provided cleaning products.

iMakerTrack operational data were pulled from its server, as seen in Figure 12, in order to compare its activities before and after COVID-19 precautions. It is important to note that a pattern is visible for this plot. For the first three quarters of the year 2020, the number of printing requests is much lower than any other quarters due to the nature of the increased number of online courses. Several of the courses were not able to require any fabrication activity. Every year, there are certain periods such as the late Fall semester which have higher submissions than at other times due to the nature of class projects, capstones, and assignments. During breaks, the data drop significantly, indicating that prints have dropped down due to students not being on campus during that time. One special note in particular requires looking at the periods of 10/19-12/19 and 10/20-12/20, which saw that an increase of about 15 iMakerTrack submissions originated from the course term projects, capstones and laboratory assignments in several hands-on courses such as Metal Casting and Computer Aided Design for Technology. Given that the last period, $1 / 21-3 / 21$ (current) is not finalized (3/11/2021), it is expected to perform similarly, since it is only three submissions away from being on par with the previous period in 2019. If this is the case, we will have confirmation that the iMakerTrack virtual print submission activity could have been a result of COVID-19 precautions.

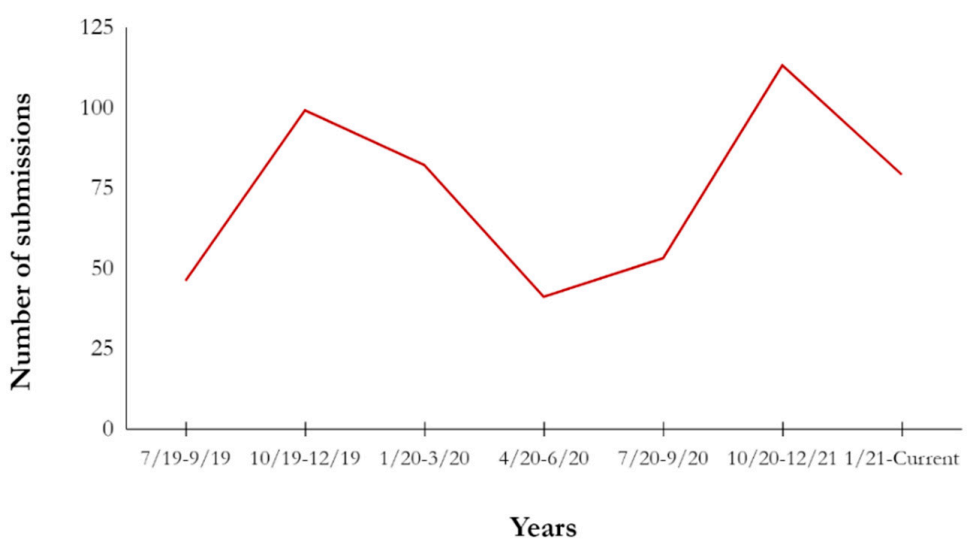

Figure 12. iMakerTrack submission numbers throughout COVID-19.

Although foot traffic to the MS saw a slight decrease, there was no sharp decrease in the amount of prints being submitted to the space as a result of COVID-19 overall; in fact, the number of prints actually saw a slight increase over the previous months. This increase is largely due to increased awareness of the space through communication of departments both inside and outside the College of Engineering. Regardless of the physical interaction within the MS, the number of virtual submissions verifiably saw an increase during the months when COVID-19 precautions were implemented. This figure was clear starting from the second quarter of 2020. Figure 13 reports the usage statistics of the iMakerSpace for the last few years. 


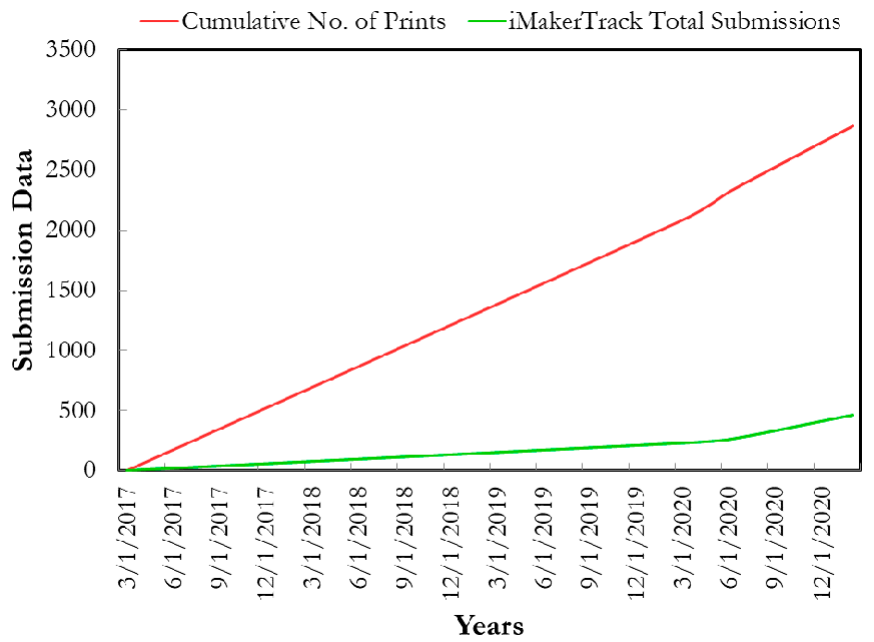

Figure 13. Usage statistics of the iMakerSpace.

\section{8. iMakerSpace Sustainability}

In order to support the needs of regional industry, several small-scale parts were printed and delivered to design and manufacturing companies. Furthermore, campus professors who needed fabricated parts for their research and consulting projects used the space. The revenue generated was used to cover the supplies and consumables of the MS.

Students working in the space have designed and prototyped "Tech Tables" to establish a small-scale sustainability model. They were designed and fabricated to latch onto the side of beds and provide a handy charging station for cell phones and other personal effects. They are sold for USD 10 at the iMakerSpace, and over the years there have been dozens sold, filling the immediate needs of the space as a sustainable model. Figure 14 shows the flyer for the Tech Table built by the iMakerSpace team members.

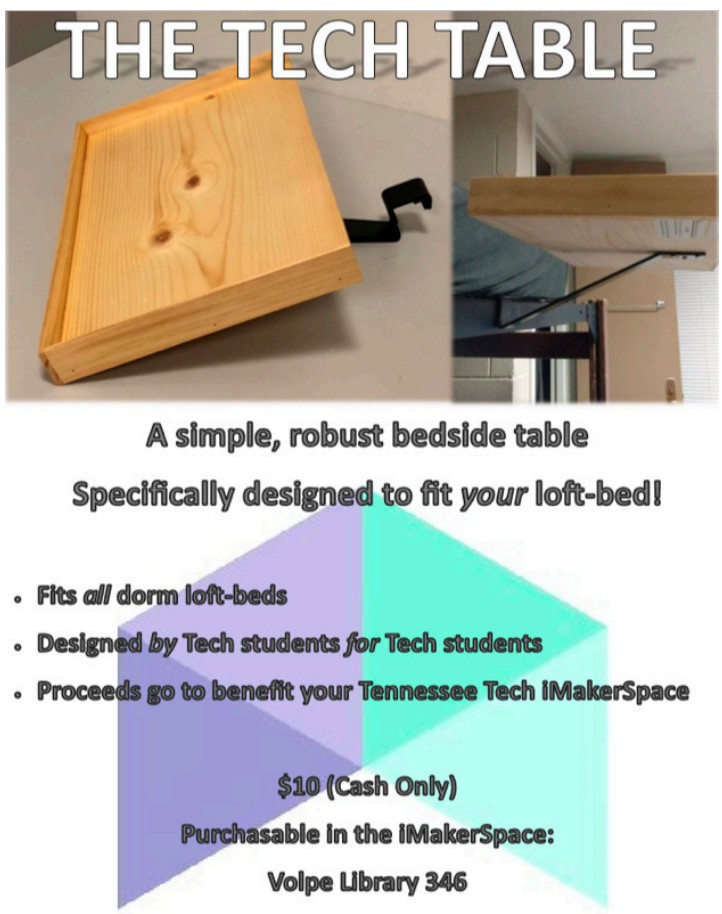

Figure 14. The Tech Table flyer.

\section{Evaluation Study}

Included in this section are the results of a survey that was administered to users of the Tennessee Tech University iMakerSpace under the COVID-19 regulations. The 
purpose of the survey was to gauge the level of use and effectiveness of the iMakerSpace by students, faculty and alumni. The survey instrument was developed by the authors, with the purpose of characterizing local uses of the MS, and to understand the particular needs of the users of this space. Content validity of the instrument was ascertained through a number of revisions completed by the stakeholders, including experts in research and survey design. Being part of a larger funded project, the evaluation study was certified as exempt by the institution's Institutional Review Board (IRB). The survey was anonymous and administered via Qualtrics. It was sent to a total of 35 people, 18 of whom responded. Of the 18 respondents, five were students, and three were either alumni, staff, or faculty. Five others (who were presumably students) selected Maker Members, work-study, and student assistant. The other five did not respond to the question. While the sample size is relatively small, it satisfied the purpose of the evaluation study, that is, to describe how the MS is utilized, and there was no intent to generalize the findings beyond this sample.

In the survey instrument, respondents were asked to rank several elements of the iMakerSpace to indicate which items had been of the most benefit to them. Figure 15 shows the percent of respondents who included each of the items in their top three rankings.

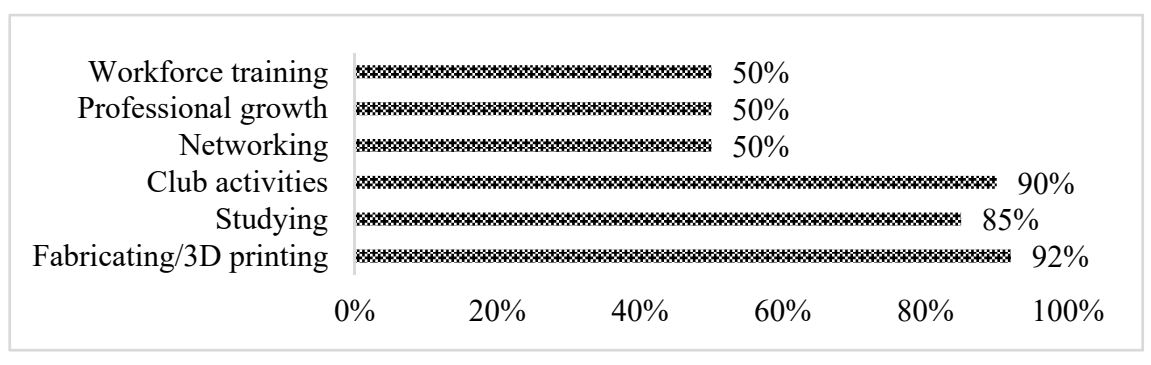

Figure 15. Percent of respondents ranking each item in their top three.

As shown in Figure 15, in the order of the highest ranked items, users of the iMakerSpace selected the following as the most beneficial to them.

- Fabricating/3DP $(92 \%)$

- Club activities (90\%)

- $\quad$ Studying $(85 \%)$

- Networking (50\%)

- Professional growth $(50 \%)$

- Workforce training $(50 \%)$

Respondents were presented with a number of items and asked to indicate whether they had gained that experience from the iMakerSpace. Table 1 shows the percentages who responded with a yes or no to each of the items. In addition to hands-on skills in 3DP and troubleshooting in printing, other noteworthy experiences the respondents selected were networking and teamwork. Users also indicated learning research skills from the iMakerSpace.

Table 2 shows the percentage and count of iMakerSpace users who took part in each of the events listed.

In response to an open-ended item about improvements that they could make to the iMakerSpace, respondents' main request was to add more 3D printers, including a metal 3D printer. Other suggestions were to have more and better advertising of the space, to increase supplies for the facility, to add a laser cutter, and enhance other matters e.g., improving accessibility to the space, having more events, and making the environment more relaxing. Overall, the comments provided were positive and constructive, and they reflected the hard work and services presented by the management team. 
Table 1. Percentage of iMakerSpace users who experienced each of the listed items.

\begin{tabular}{cccc}
\hline & Yes & No & Count \\
\hline Hands-on skills in 3DP & $92 \%$ & $8 \%$ & 13 \\
Hands-on skills in solid modeling & $58 \%$ & $42 \%$ & 12 \\
Hands-on skills in post processing & $62 \%$ & $38 \%$ & 13 \\
Networking & $54 \%$ & $46 \%$ & 13 \\
Teamwork & $77 \%$ & $23 \%$ & 13 \\
Troubleshooting in printing & $85 \%$ & $15 \%$ & 13 \\
Research skills & $85 \%$ & $15 \%$ & 13 \\
\hline
\end{tabular}

Table 2. Distribution of respondents by their participation in iMakerSpace events.

\begin{tabular}{cccc}
\hline & Yes & No & Count \\
\hline EagleWorks & $36 \%$ & $64 \%$ & 11 \\
Club meetings & $75 \%$ & $25 \%$ & 12 \\
Pancake open houses & $54 \%$ & $46 \%$ & 13 \\
Additively Innovative lectures & $46 \%$ & $54 \%$ & 13 \\
Workforce training activities & $42 \%$ & $58 \%$ & 12 \\
Student research projects & $67 \%$ & $33 \%$ & 12 \\
Manufacturing days & $38 \%$ & $62 \%$ & 13 \\
Product demonstrations & $31 \%$ & $69 \%$ & 13 \\
\hline
\end{tabular}

Due to the COVID-19 restrictions of the university, the MS was not able to offer its regular hands-on summer workshops in 2020. The management team decided to offer its regular 3DP workshop in January 2021. The main findings from the evaluation survey completed by 11 participants who attended the workforce development program held in January of 2021 were very positive. Five of the participants attended in person, and six attended virtually via Zoom. Of the 11 participants, nine $(82 \%)$ were male, and two $(18 \%)$ were female. The racial breakdown was $64 \%$ White $(n=7), 27 \%(n=3)$ Black or African American, and 9\% $(n=1)$ Hispanic. With regards to workshop content, the items assessed were quality of instruction, the relevance of topics covered to the respondents' work, the content of the training, and the extent to which the objectives were met. Most of the participants had very high satisfaction on all of these items. These findings are illustrated in Figure 16.

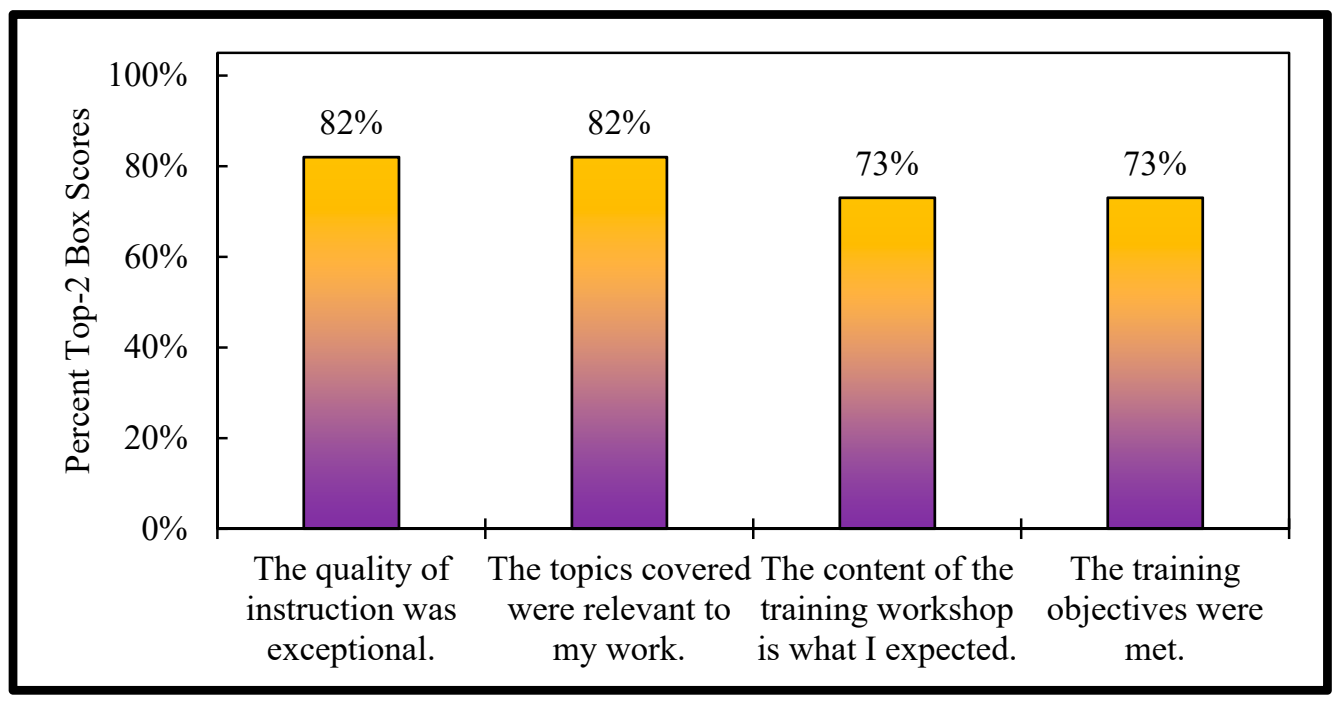

Figure 16. Percent of positive responses on workshop content.

In Fall 2020, the Additively Innovative Virtual Lecture Series was evaluated. Online survey responses were collected from the participants at the end of three virtual lectures: 
- Mass Production and Decision Making with Low-Cost Additive Manufacturing for Institutions and Small Businesses with Eric Wooldridge

- New Product Development for Additive Manufacturing: Methods and Tools with Steinar Killi

- Machine Learning in Additive Manufacturing with Ian Gibson

The survey tool released at the end of each virtual lecture was very brief. Among other things, participants were asked to report on their understanding of the topic before and after the lecture. Figure 17 shows that most participants expressed an increased understanding of each of the topics. Due to the complexity of the last topic on machine learning, the responses were not as high as others. It was clear that it was not possible to provide an in-depth knowledge of machine learning in a short period of time. The team expects to offer more virtual lectures on this topic in the future.

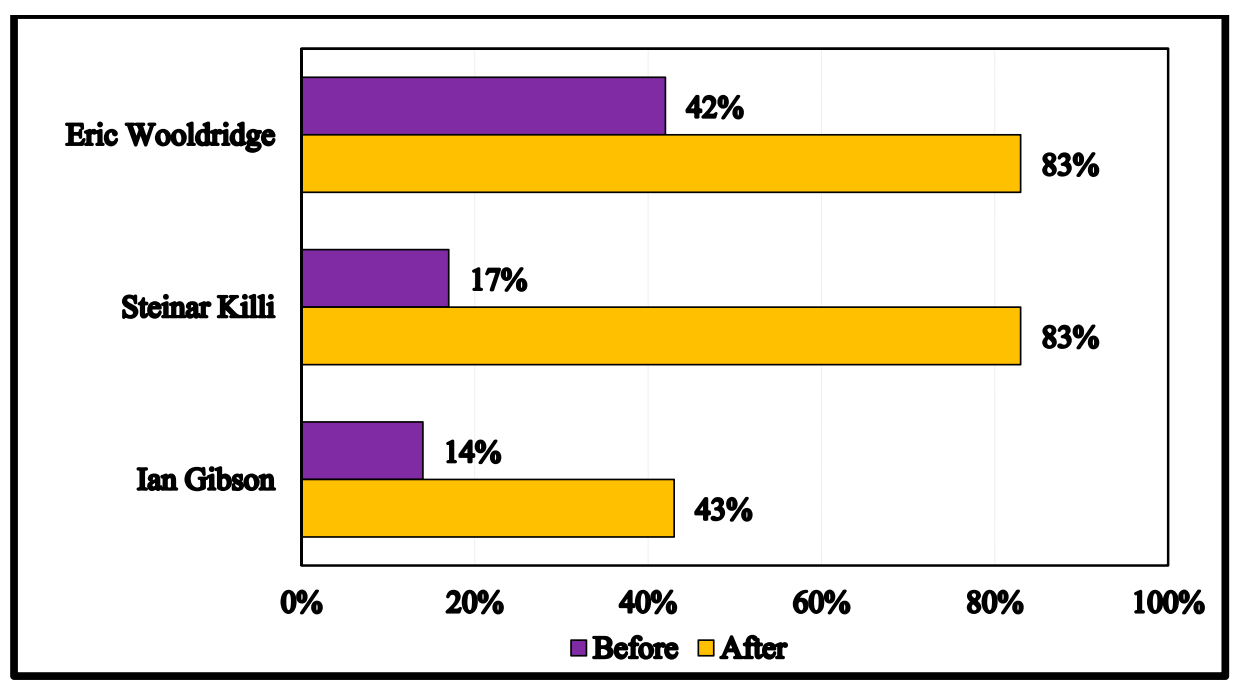

Figure 17. Percentage of respondents who reported a proficient or advanced understanding of the topic before and after each lecture.

\section{Conclusions}

MSs are becoming an essential part of post-secondary education in supporting educational delivery. Their contribution to curricular and extracurricular delivery, hands-on learning skills and creativity is reported to be high. The iMakerSpace model focused on innovative workforce development in several curricular and extracurricular settings and proved that it has been very well received by students and educators, even under COVID-19 outbreak restrictions. Although there is still a need for more diverse manufacturing equipment, such as laser cutting machines, the reported activities and innovations of the iMakerSpace were proven to be beneficial to the users, and they are effective in engaging students and sustaining operations.

Author Contributions: Writing-original draft preparation and revision, I.F., S.C., V.M., G.C. and M.M. All authors have read and agreed to the published version of the manuscript.

Funding: This research received no external funding.

Institutional Review Board Statement: Not applicable.

Informed Consent Statement: Not applicable.

Data Availability Statement: Not applicable.

Acknowledgments: The data, information, and editing provided by Elizabeth Powell, Terry Guo, Hunter Hinshaw, Robert Shelton, and Krista Davis are greatly appreciated.

Conflicts of Interest: The authors declare no conflict of interest. 


\section{References}

1. Saorín, J.L.; Melin-Diaz, D.; Bonnet, A.; Carrera, C.C.; Meier, C.; Torre-Cantero, J.D. Makerspace teaching-learning environment to enhance creative competence in engineering students. Think. Ski. Creat. 2017, 23, 188-198. [CrossRef]

2. Han, S.Y.; Yoo, J.; Zo, H.; Ciganek, A.P. Understanding makerspace continuance: A self-determination perspective. Telemat. Inform. 2017, 34, 184-195. [CrossRef]

3. Gierdowski, D.; Reis, D. The MobileMaker: An experiment with a mobile makerspace. Library Hi Tech 2015, 33, 480-496. [CrossRef]

4. $\quad$ Lagoudas, M.Z.; Froyd, J.E.; Wilson, J.L.; Hamilton, P.S.; Boehm, R.; Enjeti, P. Assessing impact of maker space on student learning. In Proceedings of the 2016 ASEE Annual Conference and Exposition, New Orleans, LA, USA, 26-29 June 2016.

5. Kurti, R.S.; Kurti, D.L.; Fleming, L. The philosophy of educational makerspaces part 1 of making an educational makerspace. Teach. Libr. 2014, 41, 8-11.

6. Oliver, K.M. Professional development considerations for makerspace leaders, part one: Addressing "what?" and "why?". TechTrends 2016, 60, 160-166. [CrossRef]

7. Oliver, K.M. Professional development considerations for makerspace leaders, part two: Addressing "how?". TechTrends 2016, 60, 211-217. [CrossRef]

8. Reading, W.I.M.; Hour, G. A Brief History of Makerspaces. Available online: https://curiositycommons.wordpress.com/a-briefhistory-of-makerspaces (accessed on 5 April 2021).

9. Clark, M. Libraries \& Makerspaces: A Revolution? Available online: https://tascha.uw.edu/2014/06/libraries-makerspaces-arevolution/ (accessed on 5 April 2021).

10. Barrett, T.W.; Pizzico, M.C.; Levy, B.; Nagel, R.L.; Linsey, J.S.; Talley, K.G.; Forest, C.R.; Newstetter, W.C. A Review of University Maker Spaces. In Proceedings of the 2015 ASEE Annual Conference and Exposition, Seattle, WA, USA, 14-17 June 2015.

11. Culpepper, M.L. Types of Academic Makerspaces, Their Import to the Education Mission, and The Characteristics of Their Culture and Community. In Proceedings of the 1st International Symposium on Academic Makerspaces, Cambridge, MA, USA, 13-16 November 2016; pp. 10-13.

12. Preddy, L. Creating school library "makerspace". Sch. Libr. Mon. 2013, 29, 41-42.

13. Brady, T.; Salas, C.; Nuriddin, A.; Rodgers, W.; Subramaniam, M. Make Ability: Creating accessible makerspace events in a public library. Public Libr. Q. 2014, 33, 330-347. [CrossRef]

14. Colegrove, T. Editorial board thoughts: Libraries as makerspace? Inf. Technol. Libr. 2013, 32, 2-8. [CrossRef]

15. Khalifa, S.; Brahimi, T. Makerspace: A novel approach to creative learning. In Proceedings of the 2017 Learning and Technology Conference (L\&T)-The MakerSpace: From Imagining to Making! Jeddah, Saudi Arabia, 27-28 February 2017.

16. Wohlwend, K.E.; Peppler, K.A.; Keune, A. Making sense and nonsense: Comparing mediated discourse and agential realist approaches to materiality in a preschool makerspace. J. Early Child. Lit. 2017, 17, 444-462. [CrossRef]

17. Britton, L. The makings of maker spaces, part 1: Space for creation, not just consumption. Libr. J. 2012, 137, 20-23.

18. Moorefield-Lang, H. Change in the making: Makerspaces and the ever-changing landscape of libraries. TechTrends 2015, 3, 107-112. [CrossRef]

19. Galaldin, M.; Bouchard, F.; Anis, H.; Lague, C. The Impact of Makerspaces on Engineering Education. In Proceedings of the Canadian Engineering Education Association (CEEA), Halifax, NS, Canada, 19-22 June 2016.

20. Smay, D.; Walker, C. Makerspaces: A creative approach to education. Teach. Libr. 2015, 42, 39-43.

21. Pettersen, I.B.; Kubberod, E.; Vangsal, F.; Zeiner, A. From making gadgets to making talents: Exploring a university makerspace. Educ. Train. 2019, 62, 145-158. [CrossRef]

22. Wong, A.; Partridge, H. Making as learning: Makerspaces in universities. Aust. Acad. Res. Libr. 2016, 47, 143-159. [CrossRef]

23. Additively Innovative Lecture Series Archive. Available online: https://www.tntech.edu/engineering/research/cmr/additivelyinnovative-archive.php (accessed on 5 April 2021).

24. Golden Eagle Additively Innovative Lecture Series-YouTube. Available online: https://www.youtube.com/channel/UC7 EDehm7-uW68FScbRFACiA (accessed on 5 April 2021).

25. Tennessee Tech College of Engineering Team Wins Leighton E. Sissom Innovation and Creativity Award. Available online: http: / 4teamm.org/news/2020/03/05/tennessee-tech-college-of-engineering-team-wins-leighton-e-sissom-innovationand-creativity-award/ (accessed on 5 April 2021).

26. Eagle Works. Available online: https://www.tntech.edu/innovation/eagleworks/ (accessed on 5 April 2021). 